\title{
RETRACTED ARTICLE: Adoption of E-Learning during Lockdown in India
}

\author{
Sandeep Kumar Mathivanan ${ }^{1}$ (1) $\cdot$ Prabhu Jayagopal $^{1} \cdot$ Shakeel Ahmed $^{2} \cdot$ \\ S. S. Manivannan ${ }^{1} \cdot$ P. J. Kumar ${ }^{1} \cdot$ Kiruba Thangam Raja $^{1} \cdot$ S. Sree Dharinya ${ }^{1}$. \\ R. Giri Prasad ${ }^{3}$
}

Received: 29 November 2020/Revised: 29 January 2021/Accepted: 12 February 2021 / Published online: 24 February 2021 (C) The Society for Reliability Engineering, Quality and Operations Management (SREQOM), India and The Division of Operation and Maintenance, Lulea University of Technology, Sweden 2021

The Editor-in-Chief and the publisher have retracted this article. The article was submitted to be part of a guestedited issue. An investigation by the publisher found a number of articles, including this one, with a number of concerns, including but not limited to compromised editorial handling and peer review process, inappropriate or irrelevant references or not being in scope of the journal or guest-edited issue. Based on the investigation's findings

Sandeep Kumar Mathivanan

sandeepkumarm322@gmail.com

Prabhu Jayagopal

jprabhuit@gmail.com

Shakeel Ahmed

shakeel@kfu.edu.sa

S. S. Manivannan

manivannan.ss@vit.ac.in

P. J. Kumar

pjkumar@vit.ac.in

Kiruba Thangam Raja

rkirubathangam@vit.ac.in

S. Sree Dharinya

ssreedharinya@vit.ac.in

R. Giri Prasad

raagurgiriprasad@prakasamec.com

1 School of Information Technology and Engineering, Vellore Institute of Technology, Vellore, TamilNadu, India

2 College of Computer Sciences and Information Technology, King Faisal University, Al-Ahsa, Kingdom of Saudi Arabia

3 Department of Electrical and Computer Engineering, Prakasam Engineering College, Kandukur, Andhra Pradesh, India the Editor-in-Chief therefore no longer has confidence in the results and conclusions of this article.

The authors Sandeep Kumar Mathivanan, Kiruba Thangam Raja, Prabhu Jayagopal and Shakeel Ahmed disagree with the retraction. The authors R. Giri Prasad, P.J. Kumar, S.S Manivannan and S. Sree Dharinya have not responded to correspondence regarding this retraction.

The online version of this article contains the full text of the retracted article as Supplementary Information.

Supplementary Information The online version contains supplementary material available at https://doi.org/10.1007/s13198-02101072-4. 